\title{
Hubungan Tingkat Kepuasan Pasien Dengan Pelayanan Asuhan Keperawatan Pada Pasien Kelas 3 Di Ruang Dahlia Rsud Dr. Doris Sylvanus Palangka Raya
}

\author{
Melisa Frisilia $^{1,}$ Rizki Muji ${ }^{2}$,Lisda Siringringo ${ }^{3}$ \\ ${ }^{1}$ STIKES Eka Harap Palangka Raya \\ ${ }^{2}$ Program Studi Sarjana Kesehatan Masyarakat \\ ${ }^{3}$ Program Studi Sarjana Keperawatan
}

DOI: $\underline{10.33859 / \mathrm{dksm} . v 11 \mathrm{i} 1.613}$

\begin{abstract}
ABSTRAK
Latar Belakang :Kepuasan pasien adalah tingkat perasaan senang seseorang yang berasal dari perbandingan antara kesenangan dan harapannya serta pelayanan kesehatan merupakan derajat dipenuhinya kebutuhan masyarakat atau perorangan terhadap asuhan kesehatan yang sesuai dengan standar profesi yang baik. Asuhan keperawatan merupakan seluruh rangkaian proses keperawatan yang diberikan kepada pasien yang berkesinambungan yang di mulai dari pengkajian sampai dengan evaluasi dalam usaha memperbaiki ataupun memelihara derajat kesehatan yang optimal. Tujuan penelitian adalah untuk mengetahui apakah ada hubungan antara kepuasan pasien dengan pelayanan asuhan keperawatan RSUD dr. Doris Sylvanus palangka raya.

Metode: Metode penelitian yang digunakan adalah korelasional dengan menjelaskan hubungan antara kepuasan pasien dengan pelayanan asuhan keperawatan. Sampel berjumlah 30 responden dengan tehnik sampling Purposive Sampling. Analisa data menggunakan uji Spearman's Rho.

Hasil: Menunjukkan hubungan korelasi di tunjukkan oleh angka ( $p$ value $=0,000<\alpha 0,05$ ), secara statistik ada hubungan korelasi bermakna antara variabel kepuasan pasien dan pelayanan asuhan keperawatan.

Kesimpulan: Peningkatan kualitas pelayanan kesehatan yang berada di rumah sakit dapat ditingkatkan dengan lebih memperhatikan hal-hal yang dibutuhkan oleh pasien seperti kenyaman pasien dalam mendapatkan pelayanan asuhan keperawatan di rumah sakit. Implikasi hasil penelitian menunjukkan kepuasan pasien sangat berkaitan dengan pelayanan asuhan keperawatan. Di rekomendasikan bagi pihak perawat untuk meningkatkan pelayanan kesehatan dalam meningkatkan kepuasan pasien.

Kata Kunci : Kepuasan Pasien, Pelayanan Asuhan Keperawatan
\end{abstract}




\begin{abstract}
Background: Patient satisfaction is the level of a person's feeling of pleasure that comes from the comparison between pleasure and hope and health care is the degree to which the needs of the community or individual for health care are in accordance with good professional standards. Nursing care is a whole series of nursing processes that are given to patients who are continuous from the assessment to evaluation in an effort to improve or maintain an optimal level of health.

Purpose: The purpose of the study was to determine whether there was a relationship between patient satisfaction with the nursing care services of RSUD dr. Doris Sylvanus palangka raya. The research method used is correlational by explaining the relationship between patient satisfaction and nursing care services. The sample consisted of 30 respondents with purposive sampling technique. Data analysis uses Spearman's Rho test.

Resesult: Shows the correlation relationship shown by the number ( $p$ value $=0,000<\alpha 0,05$ ), statistically there is a significant correlation between the variables of patient satisfaction and nursing care services. Improving the quality of health services in hospitals can be improved by paying more attention to the things needed by patients such as the comfort of patients in getting nursing care services in the hospital.

Conclusion: Implications of research results indicate patient satisfaction is closely related to nursing care services. It is recommended for nurses to improve health services in increasing patient satisfaction.
\end{abstract}

Keywords: Patient Satisfaction, Nursing Care Services

Refrences: 26 (2003-2014)

\section{PENDAHULUAN}

Pelayanan keperawatan adalah pelayanan profesional yang diberikan oleh perawat sesuai dengan standar pelayanan yang mana pelayanan yang diterima melebihi harapan pasien (Nursalam, 2011:328). Demikian perawat harus dapat memberikan pelayanan keperawatan yang terbaik kepada pasien. Pelayanan yang bermutu merupakan salah satu komponen penentu kepuasan pasien dirumah sakit. Kepuasan pasien adalah suatu tingkat perasaan pasien yang timbul sebagai akibat dari kinerja layanan kesehatan yang diperolehnya setelah pasien membandingkannya dengan apa yang diharapkannya (S. Pohan. 2003:178). Fenomena yang terjadi yaitu Pasien tidak puas karena ruangan penuh sehingga merasa pelayanan perawat masih kurang baik, perawat kurang memotivasi pasien untuk sembuh, perawat kurang memenuhi kebutuhan pasien selama dalam perawatan, dan perawat masih ada yang kurang perhatian ke pasien. Dari fenomena tersebut menunjukkan masih ada perawat kurang 
meningkatkan pelayanan asuhan keperawatan yang diharapkan pasien.

Beberapa hasil penelitian menunjukan data tentang tingkat kepuasan pasien di berbagai Negara. Tingkat kepuasan pasien menurut Ndambuki tahun 2013 di Kenya menyatakan 40,4\%, kepuasan pasien di Bakhtapur India menurut Twayana 34,4\%., sedangkan di Indonesia menunjukkan angka kepuasaan pasien $42,8 \%$ di Maluku Tengah dan 44,4\% di Sumatra Barat (Latupono, 2014 ; Sari, 2014). Berdasarkan data tersebut dapat disimpulkan bahwa angka kepuasaan pasien masih tergolong rendah, sehingga kepuasaan pasien menjadi permasalahan rumah sakit baik di Indonesia maupun di luar negeri. Menurut penelitian Huber (1996, dalam Kamaruzzaman, 2009) mengatakan bahwa sebanyak $90 \%$ pelayanan yang dilakukan di rumah sakit adalah pelayanan keperawatan. Pelayanan keperawatan yang diberikan akan berdampak pada pasien sebagai penerima jasa layanan keperawatan. Dampak yang terjadi jika pelayanan asuhan keperawatan yang diberikan tidak baik akan merasa enggan untuk kembali berobat ke rumah sakit tersebut (Azwar, 1997 dalam Kamaruzzaman, 2009). Pelayanan keperawatan adalah upaya yang dilakukan perawat untuk memenuhi kebutuhan dasar manusia. Dari survey yang dilakukan peneliti pada tanggal 10 Februari 2018 di ruang Dahlia RSUD dr Doris Sylvanus Palangka Raya kepada 10 orang pasien 7 orang diantaranya mengatakan kurang puas dengan pelayanan keperawatan karena perawat kurang meningkatkan pelayanan asuhan keperawatan 3 orang diantaranya mengatakan puas terhadap pelayanan asuhan keperawatan yang tidak membedakan pangkat maupun golongan dari pasien lain.

Kemampuan perawat dengan memberikan pelayanan yang baik terhadap pasien merupakan faktor penyebab kepuasan yang akan dirasakan oleh pasien dan mendorong untuk mempercepat kesembuhan. Penelitian Leininger tentang keberagaman kultur di dunia menemukan bahwa pelayanan membantu melindungi, membangun, peduli, dan menjaga kelangsungan hidup manusia. Pelayanan penting untuk pemulihan dari sakit dan mengelola praktik hidup sehat pada semua kultur (Potter dan Perry, 2009). Kepuasan pasien ini didapatkan melalui pelayanan keperawatan yang baik, yang penuh perhatian, persahabatan, empati dan simpati.

Sebagai tenaga kesehatan perawat di tuntut untuk dapat memberikan pelayanan keperawatan pada pasien secara semaksimal mungkin, dimana peran perawat adalah sebagai pemberi asuhan keperawatan (care giver) yang harus dapat memperhatikan keadaan kebutuhan dasar manusia yaitu dengan memperhatikan kenyamanan pasien terhadap pelayanan keperawatan yang mereka dapatkan. Persepsi pasien atau klien terhadap 
pelayanan keperawatan perlu diperhatikan oleh pemberi pelayanan keperawatan karena masyarakat yang menilai baik buruknya pelayanan di Rumah Sakit, misalnya instalasi rawat inap. Berdasarkan latar belakang diatas, penulis tertarik untuk meneliti mengenai Hubungan Tingkat Kepuasan Pasien dengan Pelayanan Keperawatan pada pasien kelas 3 di Ruang Dahlia RSUD dr. Doris Sylvanus Palangka Raya.

\section{DESAIN PENELITIAN}

Jenis penelitian yang akan digunakan adalah dengan menggunakan metode studi korelasi (Correlation Study) dengan pendekatan belah lintang (Cross Sectional) yaitu rancangan penelitian dengan melakukan pengukuran atau pengamatan pada saat bersamaan, atau melakukan pemeriksaan status paparan dan status penyakit pada titik yang sama, dengan teknik pengambilan sampel adalah pusposive sampling. Populasi pada penelitian ini adalah semua pasien yang berada di ruang di ruang Dahlia RSUD dr. Doris Sylvanus Palangka Raya.

Pengumpulan data dilakukan dengan cara dipilih oleh peneliti. Waktu penelitian ini dilakukan pada 18 - 25 Juli 2018 penelitian ini dilakukan di RSUD dr. Doris Sylvanus Palangka Raya.

Analisis multivariate ini memungkinkan kita untuk melakukan tes hipotesis tentang adanya hubungan dari dua variabel atau lebih. Disamping itu sambil melakukan kontrol terhadap variabel yang lain. Seberapa besar hubungan yang terjadi, atau bagaimana hubungan dari beberapa faktor yang terjadi secara bersama-sama. Pada penelitian ini setelah data terkumpul, kemudian dilakukan tabulasi data, dan analisa data dengan menggunakan uji statistik spearman rank dengan derajat kamaknaan $p \leq$ 0.05 . Variabel indepedent dalam penelitian ini yaitu tingkat kepuasan pasien, sedangkan variabel dependent dalam penelitian ini adalah pelayanan asuhan keperawatan pada pasien kelas 3 diruang Dahlia RSUD dr. Doris Sylvanus Palangka Raya.

\section{HASIL PENELITIAN}

\section{Data Umum}

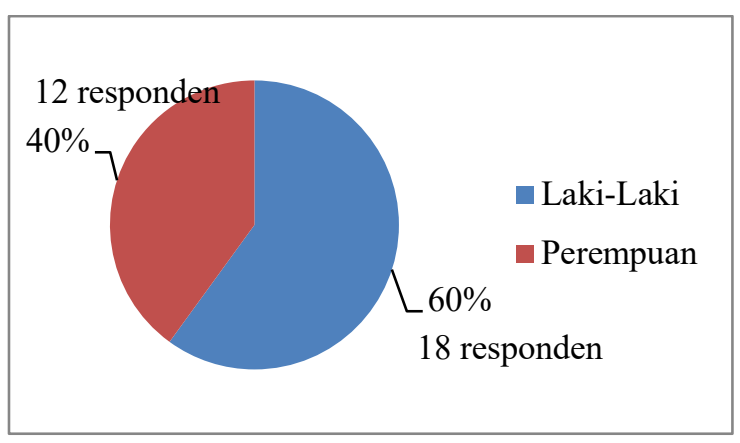

Berdasarkan data diatas dengan jumlah 30 responden. Dalam penelitian ini urutan responden paling banyak dengan kelompok jenis kelamin laki-laki yaitu $60 \%$ dengan jumlah 18 responden, sedangkan pada kelompok jenis kelamin perempuan yaitu $40 \%$ dengan jumlah 12 responden. 
Dinamika Kesehatan Jurnal Kebidanan dan Keperawatan Vol 11 No. 1 Juli 2020 ( ISSN: 2086-3454 EISSN: 2549-4058) url: http://ojs.dinamikakesehatan.unism.ac.id DOI : https://doi.org/10.33859/dksm.v11i1

Hubungan Tingkat Kepuasan Pasien Dengan Pelayanan Asuhan Keperawatan Pada Pasien Kelas 3 Di Ruang Dahlia RSUD Dr. Doris Sylvanus Palangka Raya

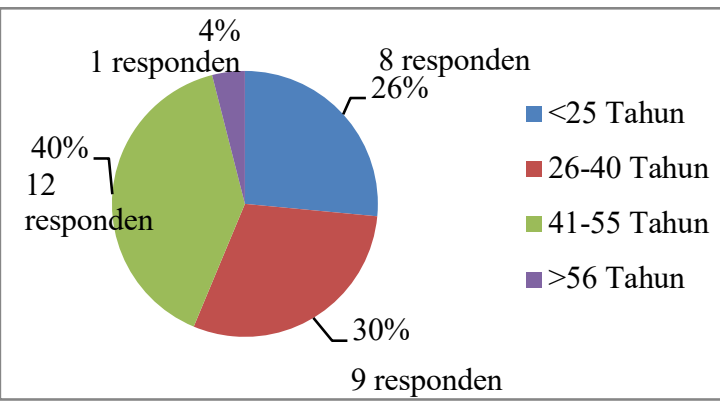

Berdasarkan data diatas dengan jumlah 30 responden. Dalam penelitian ini urutan responden paling banyak dengan kelompok umur 41-55 Tahun dengan jumlah 40\% sebanyak 12 responden, kelompok umur 26-40 tahun dengan jumlah $30 \%$ sebanyak 9 responden, kelompok umur $<25$ Tahun dengan jumlah 26\% sebanyak 8 responden, kelompok umur $>56$ Tahun dengan jumlah $4 \%$ sebanyak 1 responden.

\section{Data Khusus}

Frekuensi berdasarkan Tingkat Kepuasan Pasien di Ruang Dahlia RSUD dr.Doris Sylvanus Palangka Raya.

\begin{tabular}{|l|c|c|}
\hline $\begin{array}{c}\text { Tingkat Kepuasan } \\
\text { Pasien di Ruang Dahlia }\end{array}$ & N & \% \\
\hline Sangat Puas (76-100\%) & 6 & $20 \%$ \\
Puas (56-75\%) & 19 & $63 \%$ \\
Kurang Puas (40-55\%) & 5 & $17 \%$ \\
Tidak Puas (40\%) & 0 & 0 \\
\hline \multicolumn{1}{|c|}{ Total } & 30 & $100 \%$ \\
\hline
\end{tabular}

Sumber : Data Primer (2018)

Berdasarkan tabel diatas dari 30 orang responden kategori tingkat kepuasan pasien yang terbanyak adalah puas yaitu sebanyak 19 responden (63\%), sangat puas sebanyak 6 responden (20\%), kurang puas sebanyak 5 responden (17\%) dan tidak puas sebanyak 0 responden.
Frekuensi berdasarkan Pelayanan Asuhan Keperawatan di Ruang Dahlia RSUD dr.Doris Sylvanus Palangka Raya.

\begin{tabular}{|c|c|c|}
\hline $\begin{array}{c}\text { Pelayanan Asuhan } \\
\text { Keperawatan di Ruang } \\
\text { Dahlia }\end{array}$ & N & \% \\
\hline Tinggi (76-100\%) & 7 & $23,3 \%$ \\
Sedang (51-75\%) & 20 & $66,6 \%$ \\
Rendah (<50\%) & 3 & $10 \%$ \\
\hline Total & 30 & $100 \%$ \\
\hline
\end{tabular}

Sumber : Data Primer (2018)

Berdasarkan tabel diatas dari 30 orang responden kategori pelayanan asuhan keperawatan yang terbanyak adalah Sedang yaitu sebanyak 20 responden $(66,6 \%)$, Tinggi sebanyak 7 responden (23,3\%), dan Rendah sebanyak 3 responden (10\%).

\begin{tabular}{|c|c|c|c|c|c|c|c|c|c|}
\hline \multicolumn{7}{|c|}{ Pelayanan Asuhan Keperawatan } & \multirow{2}{*}{\multicolumn{2}{|c|}{ Total }} & \multirow{2}{*}{$\begin{array}{c}p \\
\text { valu } \\
e\end{array}$} \\
\hline $\begin{array}{l}\text { Tingkat } \\
\text { Kepuasan }\end{array}$ & \multicolumn{2}{|c|}{ Baik } & \multicolumn{2}{|c|}{ Cukup } & \multicolumn{2}{|c|}{ Kurang } & & & \\
\hline & $\mathrm{N}$ & $\%$ & $\mathrm{~N}$ & $\%$ & $\mathrm{~N}$ & $\%$ & $\mathrm{~N}$ & $\%$ & \\
\hline Sangat Puas & 6 & 20,0 & 0 & 0,0 & 0 & 0,0 & 6 & 20,0 & \\
\hline Puas & 1 & 3,3 & 15 & 50,0 & 3 & 10,0 & 19 & 63,3 & 0,000 \\
\hline $\begin{array}{l}\text { Kurang } \\
\text { puas }\end{array}$ & 0 & 0,0 & 5 & 16,7 & 0 & 0,0 & 5 & 16,7 & \\
\hline Total & 7 & 23,3 & 20 & 66,7 & 3 & 10,0 & 30 & 100 & \\
\hline
\end{tabular}

\section{a. Spearman Rank}

Berdasarkan hasil analisa uji statistik hubungan tingkat kepuasan pasien dengan pelayanan asuhan keperawatan pada pasien kelas 3 di Ruang Dahlia RSUD dr. Doris Sylvanus palangka raya tanggal 18 Juli 2018, menunjukan analisa data dengan menggunakan uji statistik spearman rank dengan nilai $p$ ( $p$ value $) \quad 0,000$ derajat kamaknaan $p \leq 0.00$ yang berarti H1 diterima 
Dinamika Kesehatan Jurnal Kebidanan dan Keperawatan Vol 11 No. 1 Juli 2020 ( ISSN: 2086-3454 EISSN: 2549-4058)

url: http://ojs.dinamikakesehatan.unism.ac.id DOI : https://doi.org/10.33859/dksm.v11i1

Hubungan Tingkat Kepuasan Pasien Dengan Pelayanan Asuhan Keperawatan Pada Pasien Kelas 3 Di Ruang Dahlia RSUD Dr. Doris Sylvanus Palangka Raya

sehingga terdapat hubungan yang signifikan antara kedua variabel kepuasan pasien dengan variabel pelayanan asuhan keperawatan.

\section{PEMBAHASAN}

Berdasarkan tabel 4.3, pada tingkat kepuasan pasien dengan pelayanan asuhan keperawatan didapatkan hasil dari tingkat kepuasan pasien kategori sangat puas dengan pelayanan asuhan keperawatan kategori baik 6 responden $(20,0 \%)$, cukup 0 responden $(0,0 \%)$, kurang 0 responden $(0,0 \%)$. Dengan tingkat kepuasan kategori puas dengan pelayanan asuhan keperawatan kategori baik 1 responden (3,3\%), cukup 15 responden 50,0\%, kurang 3 responden $10,0 \%$. Dengan tingkat kepuasan pasien kategori kurang puas dengan pelayanan asuhan keperawatan kategori baik 0 responden $(0,0 \%)$, cukup 5 responden (16,7\%), kurang 0 responden $(0,0 \%)$.

Hasil uji statistik di peroleh nilai $\mathrm{p}=$ $0,000<\alpha(0,01)$ yaitu $\mathrm{p}$ value $<\alpha(0,01)$ dan correlation coefficient 0,614 maka $\mathrm{H}_{1}$ diterima, dari hasil tersebut menunjukkan maka adanya hubungan yang signifikan antara tingkat kepuasan pasien dengan pelayanan asuhan keperawatan di ruang dahlia RSUD dr.Doris Sylvanus Palangka Raya.

Kepuasan bisa diartikan sebagai upaya pemenuhan sesuatu atau membuat sesuatu yang memadai. Pasien baru akan merasa puas apabila kinerja pelayanan kesehatan yang diperolehnya sama atau melebihi harapanya dan sebaliknya, ketidakpuasan atau perasaan kecewa pasien akan muncul apabila kinerja layanan kesehatan yang diperolehnya itu tidak sesuai dengan harapannya. Berdasarkan apa yang disebutkan diatas, pengertian kepuasan pasien dapat dijabarkan sebagai berikut. Kepuasan pasien adalah suatu tingkat perasaan pasien ang timbul sebagai akibat dari kinerja layanan kesehatan yang diperolehnya setelah pasien membandingkannya dengan apa yang diharapkannya.

Hasil dari tingkat kepuasan pasien dalam kategori sangat puas dan pelayanan asuhan keperawatan kategori baik 6 responden $(20,0 \%)$ dikarenakan pasien sangat puas dengan pelayanan asuhan keperawatan yang diberikan perawat di Ruang Dahlia sehingga pasien merasakan keinginan nya agar cepat sembuh terpenuhi dengan tingginya kepuasan pasien dengan pelayanan asuhan keperawatan tersebut.

Hasil dari tingkat kepuasan pasien dalam kategori puas dan pelayanan asuhan keperawatan kategori baik 1 responden $(3,3 \%)$ dikarenakan pasien puas dengan pelayanan asuhan keperawatan yang diberikan perawat diruang dahlia sehingga pasien merasakan keinginan dirinya yang dirawat oleh perawat agar cepat sembuh terpenuhi dengan tingginya pelayanan asuhan keperawatan akan memberikan kepuasan bagi pasien. 
Hasil dari tingkat kepuasan pasien dalam kategori puas dan pelayanan asuhan keperawatan kategori cukup 15 responden $(50,0 \%)$ dikarenakan pasien puas dengan pelayanan asuhan keperawatan yang diberikan perawat diruang dahlia sehingga pasien merasakan keinginan dirinya yang dirawat oleh perawat agar cepat sembuh terpenuhi dengan tingginya pelayanan asuhan keperawatan akan memberikan kepuasan bagi pasien.

Hasil dari tingkat kepuasan pasien dalam kategori puas dan pelayanan asuhan keperawatan kategori kurang 3 responden $(10,0 \%)$ dikarenakan pasien cukup puas dengan pelayanan asuhan keperawatan yang diberikan perawat diruang dahlia sehingga pasien merasakan keinginan dirinya yang dirawat oleh perawat agar cepat sembuh terpenuhi dengan tingginya pelayanan asuhan keperawatan akan memberikan kepuasan bagi pasien.

Hasil dari tingkat kepuasan pasien dalam kategori kurang puas dan pelayanan asuhan keperawatan kategori cukup 5 responden $(16,7 \%)$ dikarenakan pasien kurang puas dengan pelayanan asuhan keperawatan yang diberikan perawat diruang dahlia sehingga pasien merasakan keinginan dirinya yang dirawat oleh perawat tidak cepat sembuh terpenuhi dengan kurang nya kepuasan bagi pasien.
Terdapat kesesuaian antara fakta dan teori, karena perasaan kepuasaan pasien yang menunjukkan pelayanan asuhan keperawatan yang diberikan perawat selama pasein dirawat diruang dahlia. Jika perawat tidak memberikan pelayanan asuhan keperawatan kepada pasien dengan benar maka pasien tersebut tidak merasa puas selama dirawat.

Semakin sangat puas kepuasan pasien dalam menerima pelayanan asuhan keperawatan, maka pasien atau keluarga semakin senang dalam menerima pelayanan dan membuat pasien semakin termotivasi untuk sembuh berarti hubungan antara perawat-klien semakin terbina, begitu juga sebaliknya semakin kurang kepuasan pasien dalam menerima pelayanan asuhan keperawatan maka pasien tidak akan puas terhadap pelayanan yang diberikan. Penelitian ini dikaitkan dengan penelitian Andy Nur Hidaya (2014), hasil penelitian menunjukkan ada hubungan pelayanan keperawatan dengan kepuasan pasien dengan nilai statistik ( $p=$ $0,00)$.

\section{SARAN}

\section{1) Bagi IPTEK}

Hasil penelitian ini dapat dipergunakan sebagai bahan acuan dan dijadikan dasar untuk memajukan dan mengembangkan ilmu pengetahuan tentang kepuasan pasien dengan pelayanan keperawatan dan 
Dinamika Kesehatan Jurnal Kebidanan dan Keperawatan Vol 11 No. 1 Juli 2020 ( ISSN: 2086-3454 EISSN: 2549-4058) url: http://ojs.dinamikakesehatan.unism.ac.id DOI : https://doi.org/10.33859/dksm.v11i1

Hubungan Tingkat Kepuasan Pasien Dengan Pelayanan Asuhan Keperawatan Pada Pasien Kelas 3 Di Ruang Dahlia RSUD Dr. Doris Sylvanus Palangka Raya

teknologi khususnya dalam bidang

kesehatan.

\section{2) Bagi Tempat Penelitian}

Penelitian di ruang dahlia memberi pelayanan yang memenuhi kebutuhan dan harapan klien, serta kepada bagian manejemen khususnya bidang keperawatan, memberi intsruksi bagaimana sikap mendengarkan dan memahami klien sebagai dua item dari kepuasan pasien, sebab kurang ditunjukkan dalam memberikan pelayanan keperawatan.

\section{3) Bagi Institusi Pendidikan STIKes Eka}

\section{Harap}

Dari hasil penelitian ini dapat dijadikan referensi yang dapat dibuat untuk acuan di masa yang akan datang oleh institusi pendidikan terutama STIKes Eka Harap Palangka Raya, bukan hanya untuk bahan bacaan tetapi juga dapat dipergunakan untuk menjadi acuan dalam pelayanan keperawatan.

\section{4) Bagi Peneliti Selanjutnya}

Bagi peneliti selanjutnya dapat menghubungkan tingkat kepuasan dengan hal lainnya seperti lingkungan dan fasilitas pelayanan.

\section{DAFTAR PUSTAKA}

Asmadi. (2008). Konsep Dasar Keperawatan. Jakarta : EGC

Carpenito, Lynda Juall. (2000). Buku Diagnosa Keperawatan : Editor Monica Ester. EGC : Jakarta

Gerson, R.F. (2004). Mengukur Kepuasan Pelangga :Panduan Menciptakan Pelayanan Bermutu. Jakarta : PPM

Hidayat, A. Aziz Alimul. (2008). Metode Penelitian Keperawatan dan Teknik Analisa Data. Jakarta: Salemba Medika

Hidayat, A. Aziz Alimul. 2011. Pengantar Konsep Dasar Keperawatan: Edisi 2. Jakarta: Salemba Medika.

Hernita, P. (2012). Panduan Praktis SPSS 20 Edisi 1. Yogyakarta: Andi; Semarang: Wahana Komputer.

Imbalo, S. (2006). Jaminan Mutu Layanan Kesehatan: Dasar-Dasar Pengertian Dan Penerapan. Jakarta : EGC.

Kotler, P. 2003. Manajemen Pemasaran. Jakarta: Prenhallindo.

Kotler, Philip Dan Kevin Lane Keiler. (2009). Manajemen Pemasaran. Jakarta : Erlangga.

Koentjoro, Tjahjono.(2011). Regulasi Kesehatan di Indonesia. Cetakan Kedua. Yogyakarta: ANDI.

Notoadmodjo Soekidjo. 2010. Metodelogi Penelitian Kesehatan. Jakarta: Rineke Cipta

Nursalam. (2008). Konsep dan Penerapan Metodologi Penelitian Ilmu Keperawatan. Jakarta: Salemba Medika 
Dinamika Kesehatan Jurnal Kebidanan dan Keperawatan Vol 11 No. 1 Juli 2020 ( ISSN: 2086-3454 EISSN: 2549-4058)

url: http://ojs.dinamikakesehatan.unism.ac.id DOI : https://doi.org/10.33859/dksm.v11i1

Hubungan Tingkat Kepuasan Pasien Dengan Pelayanan Asuhan Keperawatan Pada Pasien Kelas 3 Di Ruang Dahlia RSUD Dr. Doris Sylvanus Palangka Raya

Nursalam.(2011). Manajemen Keperawatan, Aplikasi dalam praktek keperawatan Profesional. Jakarta: Salemba Medika

Nursalam. (2013). Metodologi Penelitian Ilmu Keperawatan: Pendekatan Praktis (edisi 3). Jakarta: Salemba Medika

Pohan, Imbalo S. 2006. Jaminan Mutu Layanan Kesehatan: Dasar-Dasar Pengertian dan Penerapan. Jakarta: EGC.

Potter, Patricia A. Dan Perry Anne G. 2009. Fundamentals of Nursing: Fundamental Keperawatan Bukul Edisi 7. Jakarta: Salemba Medika.

Potter dan Perry. (2005). Buku Ajar Mental. Konsep Proses dan Praktek (edisi 4). EGC : Jakarta

Satrianegara, M. Fais. (2009). Buku Ajar Organisasi dan Manajemen Pelayanan Kesehatan Serta Kebidanan. Jakarta : Salemba Medika

Setiadi. (2007). Konsep\&Penulisan Riset Keperawatan. Yogjakarta: Graha Ilmu

Susilo, H Wilhelmus. (2013). Skala Pengukuran dan Instrumen Penelitian Aplikasi SPSS Pada Penelitian Ilmu Keperawatan. Jakarta : IN MEDIA

Susilo, H Wilhelmus. Nandan (2012). Cermat Menyusun Kuisoner Penulisan Ilmu Keperawatan. Jakarta : TIM

Supranto, J. (2006)Pengukuran Tingkat Kepuasan Pelanggan. Jakarta: Rineka Cipta.

Surya Utama. 2003. Memahami Fenomena Kepuasan Pasien. http:www.usu digitallibrary. Diakses 21 Maret 2018.
Suryawati. 2006. Penyususnan Indikator Kepuasan Pasien. Jurnal Manajemen. 8.

Tjiptono, Fandy. (2000). Manajemen Jasa. Yogyakarta : Andi 